\title{
PARK AND PARCEL: AN AGENT-BASED EXPLORATION OF LAST-MILE FREIGHT DELIVERY BEHAVIOR AS IT RELATES TO PARKING
}

\author{
Sarah Wise \\ Kostas Cheliotis \\ Centre for Advanced Spatial Analysis \\ University College London \\ London, WC1E 6BT, UK \\ \{s.wise, k.cheliotis\}@ucl.ac.uk \\ Fraser McLeod \\ Tom Cherrett \\ Transportation Research Group \\ Southampton University \\ Southampton, SO17 1BJ, UK \\ \{F.N.Mcleod, T.J.Cherrett\}@ soton.ac.uk
}

\author{
Oliver Bates \\ Energy Lancaster \\ Lancaster University \\ Lancaster, LA1 4YF, UK \\ o.bates@lancaster.ac.uk
}

Julian Allen

Maja Piecyk

Transport Studies Department

University of Westminster

London, W1B 2HW, UK

\{allenj, M.Piecyk\}@westminster.ac.uk

\author{
Tolga Bektas \\ Management School
University of Liverpool
Liverpool, L69 3BX, UK
T.Bektas@liverpool.ac.uk
}

\begin{abstract}
Light goods vehicles are an important part of London traffic. With changes to delivery demand and traffic patterns more broadly, they often have a disproportionate impact on the functioning of cities. We partnered with industrial organizations specializing in last-mile parcel delivery, thereby gaining access to data which allowed us to construct an agent-based model of the last-mile delivery process. In this work, we expand upon the existing model to incorporate parking behavior, an important factor of delivery driving which is often overlooked in the literature. The tool we present can be used to explore different policy and infrastructure interventions.
\end{abstract}

Keywords: agent-based modeling, freight, parcel delivery, last mile, parking. 
Wise, Cheliotis, Bates, McLeod, Cherrett, Allen, Piecyk and Bektas

\section{INTRODUCTION}

The city of London is not traditionally known for its quiet streets, and it is perhaps no surprise to anyone that these streets have been growing busier over the long term (Roads Task Force 2013). However, since 2007 the overall level of motorized traffic has actually shrunk, with 2015 seeing $11 \%$ less volume of traffic than 1999 (Department for Transport 2016). Freight vehicles have bucked this trend, with light goods vehicles (LGVs) even swimming against the current. LGVs have increased by a factor of 11 since the 1960s, and were responsible for $80 \%$ of total goods vehicle miles driven across London in 2015 (Allen, Piecyk, and Piotrowska 2016). While they represent only a sixth of the car traffic in London, they are responsible for 14\% of total London vehicle kilometers traveled in 2015, up from 10\% in 1993.

Not only are LGVs unusual in terms of distance driven, but their impact is felt in terms of emissions (many use diesel), safety (cyclists in particular are concerned with this; see (Allen, Browne, and Woodburn 2014)), and congestion (Allen, Piecyk, and Piotrowska 2016). Thus, not only are they important to the economic functioning of the city and the country more broadly, but they play a disproportionate role in traffic and health. However, relatively little research has previously been done into the question of LGVs, as their movements support a more diverse set of activities. (Allen, Piecyk, and Piotrowska 2016) note that LGVs are involved in "the collection and delivery of goods, the carrying out of servicing activities (and the related carriage of tools or equipment), commuting to and from a place of work (as many vans are kept at residential properties) and personal journeys (e.g. shopping and leisure journeys unconnected with work)."

Despite this disproportionate impact and importance, then, we know relatively little of LGVs and their impact on the city. To combat this relative lack of information and understanding, our project has sought to analyze the way LGVs move around the city, interacting with one another and trying to achieve their own tasks. We have done this by collecting data, analyzing it, and further modeling the system to gain a better understanding into the areas for which we lack observational data. By partnering with industrial organizations who use light goods vehicles to deliver parcels over the last mile, we are attempting to understand both how the system currently works, and how it might be restructured to allow deliveries to flow without jeopardizing health and safety.

Here, we present an extension to our previous work which allows us to more thoroughly explore how the demands of parking can influence the delivery process. We begin with a contextualization of this work within the previous body of research, then present the methodology we implement here. We present a brief overview of our current research with the model. Finally, we address the implications of this study, with an eye toward future work and how it may be combined with other techniques.

\section{BACKGROUND}

In studying the parcel delivery process, it is important to capture the ways in which the different actors within the system engage with one another. Because parcel delivery fundamentally involves the transfer of physical objects between distinct persons or organizations, it is necessary to study it with a spatial methodology capable of incorporating time into the analysis. In order to do this, we have turned to agent-based modeling.

Agent-based modeling is a tool which has the potential to bridge the gap between academics, industrial partners, and government agencies. Simulations can provide us with "artificial laboratories" to test ideas and hypotheses about phenomena which prove to be "wickedly" complex in the real world (Gilbert 2007). Combined with increasingly available big data, it can help tailor systems in order to give more specific information (Heppenstall, Malleson, and Crooks 2016). In particular, some promising work of this nature has already taken place (Chen and Chankov 2017), (Starý 2012). In order to capture the behaviorally-informed, spatio-temporal process of parcel delivery, we have constructed an agent-based modeling framework which allows us to visualize how different approaches to delivery and cooperation can translate into different out- 
comes for our industry partners as well as our urban spaces more broadly (see (Wise, Cheliotis, Bates, Friday, Allen, McLeod, and Cherrett 2018)).

Having established that there was a desire for a more rigorous statistical treatment of last-mile freight in London, our industry partners provided us with spatial data, including GPS traces of delivery vehicles and manifest delivery locations. In our initial investigations of the data provided to us by our industry partners, we found a number of surprising results. Perhaps most unexpectedly, delivery drivers were spending on average more than half of the time on their rounds with the vehicles parked. They were also walking $7.9 \mathrm{~km}$ per round on average, compared to driving $11.9 \mathrm{~km}$ within the target area. A minimum of $80 \%$ of parking stops took place in street parking situations rather than any kind of specialized loading/unloading area. Broadly, these suggested both to us and our industry partners that the drivers were going about the delivery process rather differently than expected. Parking and its availability were dynamic and influential factors in the business of delivery.

Tied up with this was the question of driver experience. It was commonly accepted wisdom among our industry partners that more experienced drivers were able to deliver more parcels more rapidly and effectively than drivers who had been working for only a few months. Despite this, it was not common for our partner carriers to utilize any form of routing and scheduling software to manage the planning and execution of the last-mile deliveries. One of the dynamics we identified from our surveys was that experienced drivers were very knowledgeable as to the location of good parking spaces, the likely locations of persistent traffic congestion, and the ways in which delivery access to a particular building could be gained (Allen, Piecyk, Piotrowska, McLeod, Cherrett, Ghali, Nguyen, Bektas, Bates, Friday, Wise, and Austwick 2018).

Table 1: Vehicle round statistics for parcel deliveries $(n=25)$ studied in central London, October 2016. Taken from (Allen, Piecyk, Piotrowska, McLeod, Cherrett, Ghali, Nguyen, Bektas, Bates, Friday, Wise, and Austwick 2018).

\begin{tabular}{lccccc}
\hline Vehicle round statistic & Min & Max & Mean & St.Dev. & Unit \\
\hline Round duration, of which: & 5.1 & 10.3 & 7.3 & 1.4 & hour \\
$\quad$ vehicle parked & $33 \%$ & $77 \%$ & $62 \%$ & $11 \%$ & $\%$ \\
Driving distance within delivery area & 3.6 & 20.5 & 11.9 & 5.1 & $\mathrm{~km}$ \\
Average vehicle speed within delivery area & 2.6 & 12.3 & 7.0 & 2.4 & $\mathrm{kph}$ \\
No. of items delivered and (collected) & $57(1)$ & $274(62)$ & $118(9)$ & $46(12)$ & $\#$ \\
Total walking distance & 4.64 & 12.48 & 7.94 & 2.32 & $\mathrm{~km}$ \\
Average walking distance per customer & 67 & 145 & 105 & 22.8 & $\mathrm{~m} / \mathrm{customer}$ \\
No. of customers served & 32 & 120 & 72 & 23 & $\#$ \\
No. of parking stops, of which: & 14 & 72 & 37 & 12 & $\#$ \\
$\quad$ proportion on street & $80 \%$ & $100 \%$ & $95 \%$ & $5 \%$ & $\%$ \\
Time taken to deliver or collect (once parked) & 1.6 & 6.8 & 4.1 & 1.2 & $\mathrm{~min} /$ customer \\
\hline
\end{tabular}

\section{METHODOLOGY}

This paper presents an extension to the baseline ABM framework developed by the FTC 2050 Project (see http://ftc2050.com). The underlying framework was initially presented in (Wise, Cheliotis, Bates, Friday, Allen, McLeod, and Cherrett 2018), and has been developed together with partners in industry. Further work into the validation and verification of the model is presented in (Wise, Cheliotis, Bates, Friday, Cherrett, McLeod, Allen, and Piecyk tion). Here, we add on an implementation of a naive version of the parking behavior we saw so clearly characterizing the movements and behavior of our target providers. The framework model simulates the behaviors of delivery staff, depots, vehicles, and parcels as individual units, capturing these dynamics at a granularity of meters and minutes. The framework model is as follows: 
- Parcels are synthetically generated based on our real data for parcel delivery demand throughout neighborhoods, then allocated to depots.

- Depots cluster parcels into groups based on a metric; in this paper, the parcels are simplistically bundled by cartesian distance from one another.

- Delivery staff enter the depots and wait to be assigned a set of parcels. Having spent a period of time collecting the parcels and potentially placing them within a vehicle, they exit the depot, making way for other delivery staff to collect their own parcels.

- Delivery personnel attempt (but sometimes fail) to distribute parcels, proceeding from one to the next based on a greedy heuristic.

- Once the delivery staff member has attempted to deliver every parcel, they return to the depot with the undelivered parcels and wait to be assigned a new round.

This process continues until the end of their shift, allowing us to follow the routine of individual staff members.

We expand upon this existing work by tweaking the routing of the delivery personnel to specifically include parking. First, we present the data which underpins this, spatially speaking. We then move on to a brief discussion of how this is implemented in the case of the model.

\subsection{Data}

It is important to note that although the development process has made use of proprietary datasets, the information used here is derived from open-source contexts. We situate this case study in and around the London Borough of Camden. This is a function of the excellent open-source data provided by the Borough regarding parking information (London Borough of Camden 2019). Through this dataset, we can bring to bear the qualitative nature of our past research on a well-documented set of spatial data. See, for example, Figure 1. The data shows the variety of types of parking bays which might conceivably be utilized by delivery drivers. The mixed use of the parking spaces is therefore particularly interesting when it comes to delivering to different parts of the area.

In this simulation, we reflect the competition for parking space with other vehicles by setting the likelihood of parking space accessibility based on the type of parking space available. For example, in the northern and more residential parts of Camden, there are a great number of mixed-use parking bays which can be used either for loading or parking. The greater likelihood of these spaces being occupied is somewhat balanced by their numerousness. This stands in contrast to the more loading-centric infrastructure in the south: parking spaces are less likely to be occupied by non-freight drivers, but are less densely distributed. It is important to note also that some parking bays have the capacity to hold more than one vehicle (see Figure 2). In these cases, the assumption is that the stochastic test is repeated for each notionally available parking space. Again, the residential north of Camden contains a number of larger parking structures, while the southern, more commercial portion has less to offer.

\subsection{Implementation of Parking Algorithm}

The drivers draw upon the parking information by adjusting their route planning to plan based not on the parcel delivery locations proper, but the nearest parking spaces. In the current implementation, that is, drivers match parking spaces to their nearest (in terms of cartesian space) parking spots and plot a route through these locations, following the same greedy heuristic of taking the closest next point as in the original 
Wise, Cheliotis, Bates, McLeod, Cherrett, Allen, Piecyk and Bektas

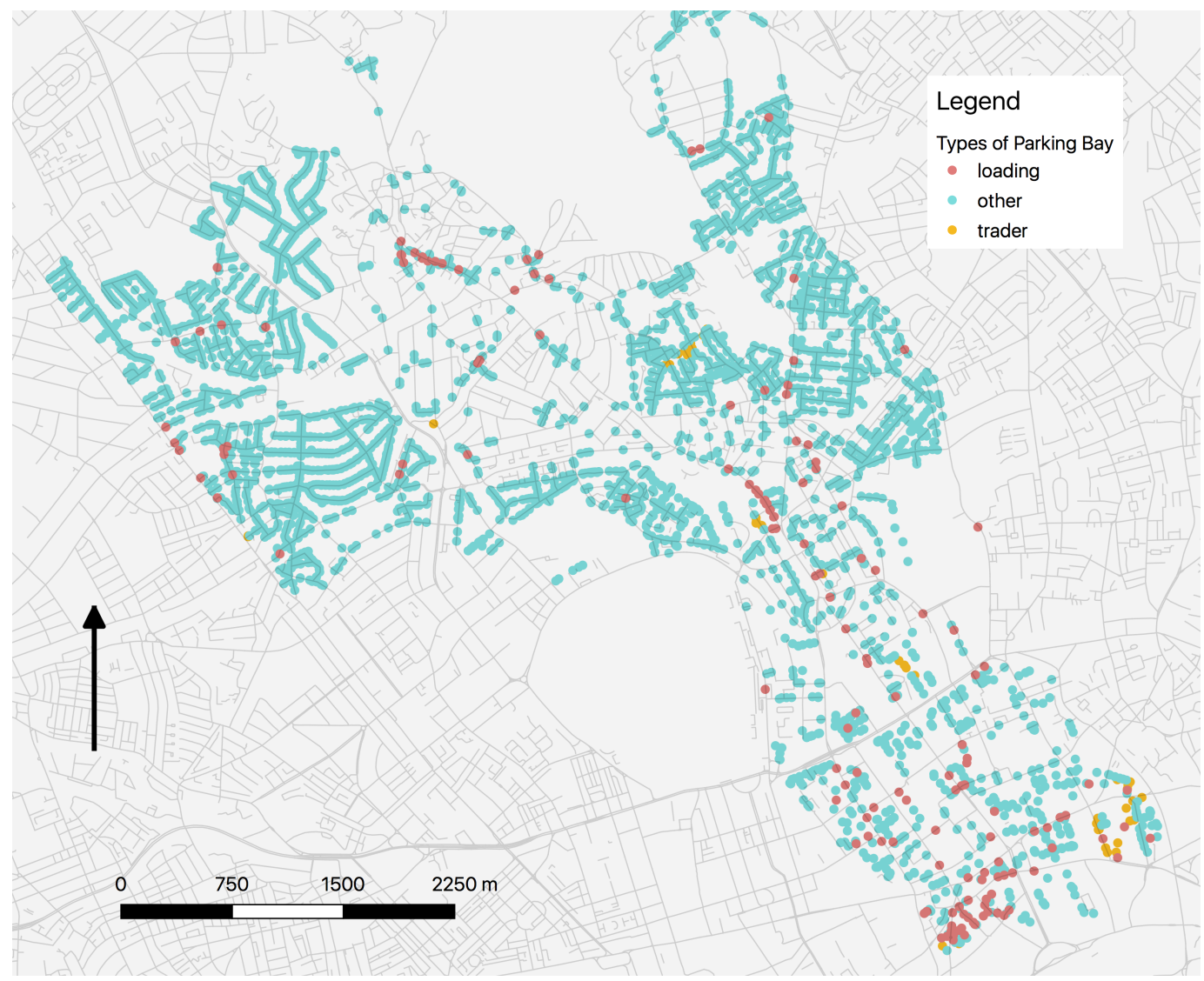

Figure 1: Parking data for Camden borough classified by type of parking bay.

work. Thus, drivers proceed along, delivering all parcels associated with a given parking location before proceeding to the next. The pseudocode for this is shown in Algorithm 1.

Result: Allocation of parcels to parking spaces and associated route clear the route;

link each parcel to all parking places within walking range of it;

sort the set of parking locations in descending order of degree;

while there are parcels without an associated parking space in the route do

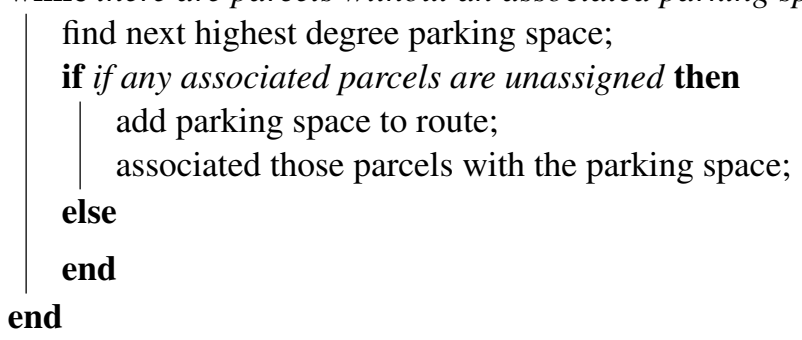

return route of parking spaces with associated parcels

Algorithm 1: Pseudocode for the route planning mechanism. 


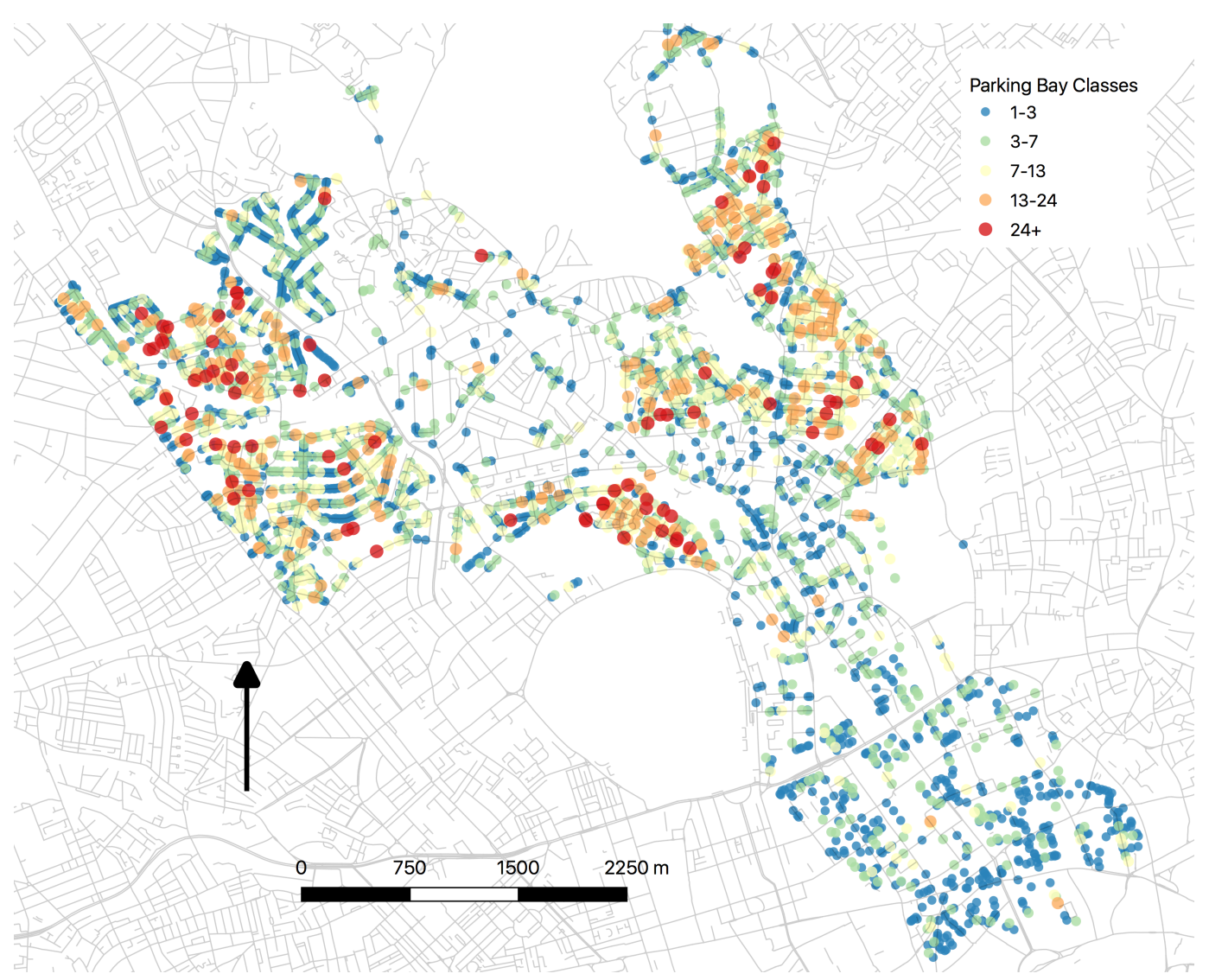

Figure 2: Parking data for Camden borough classified by number of parking spaces per bay. Categories defined by natural breaks in data.

Interacting with the parking spaces requires its own simple behavior. In particular, a driver who encounters their target parking space may find that it is already occupied. This is stochastically determined, and is motivated (as discussed in the previous section) by the type of parking space and the associated demand for it. Thus, a driver may find that the parking space is occupied, or even that it is already occupied by an existing other agent. At this point, driver "experience" enters the question. Drivers may be experienced or inexperienced, which plays an important role in parking behavior. In the case that a driver reaches a parking space and finds it already occupied by another driver, an experienced driver has to knowledge to select the next nearest parking space and attempt to park there. If the experienced driver cannot find a parking space within a certain range of the target space, they will loop around and begin attempting to park again. In contrast, an inexperienced driver only attempt to find a different parking space within a very constrained 
area before driving in a circle and waiting for the original space to become available. Pseudocode for this process is shown in Algorithm 2.

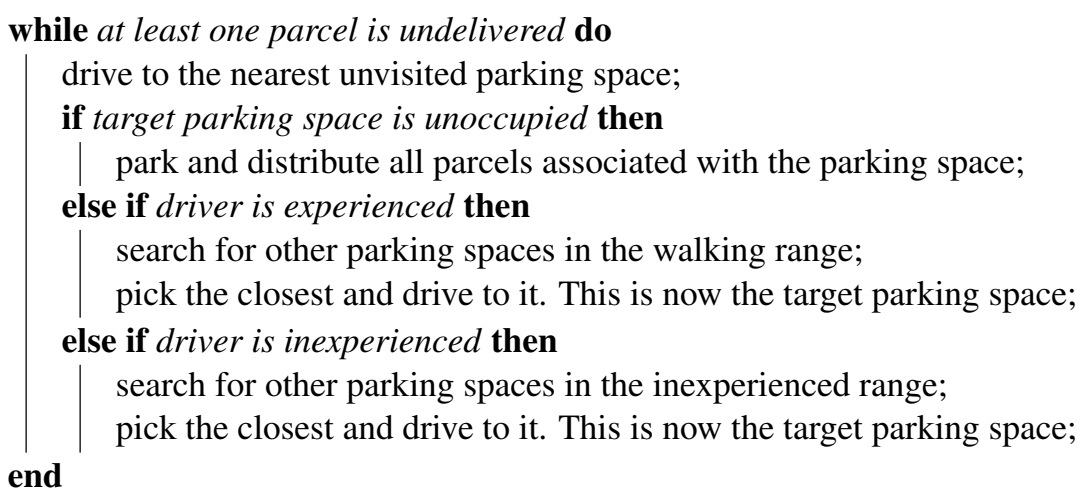

Algorithm 2: Pseudocode for the parking and delivery mechanism.

\section{CASE STUDY}

To begin with, we calibrate the extended model itself in a process known as "verification". This is the common name for ensuring that the implemented model matches the designed model. North and Macal (North and Macal 2007) define this as the case in which the code produced as part of the work correctly carries out the processes described by the authors. Verification decreases the risks of code and data artifacts, and makes for more rigorous science. Because the majority of the model has been tested in previous work (Wise, Cheliotis, Bates, Friday, Cherrett, McLeod, Allen, and Piecyk tion), here we are required to verify only the impact of the new parking behavior - a benefit of the modular approach of development. To that end, we output the individual routing and parking process of sample drivers, and compare them with our survey experience.

Beyond verification there is the process of validation - the determination whether the modeled processes produce results that resemble the real data (see (North and Macal 2007) for more). An example of the dataset used to ensure a match between synthetic and real patterns of parking is shown in Figure 3. A necessary aspect of this marriage of verification and validation is the parameter sweep, which teases out the possible unintended interactions among parameter settings. The addition of further parameters requires the exploration of their sensitivity to minor changes. In particular, we look at how varying the relative likelihoods of parking space occupancy for different parking bay types impacts the functioning of the model. Further, we vary the distances considered by experienced versus inexperienced drivers in their search for a parking space.

\section{DISCUSSION AND CONCLUSION}

This work has presented a technique for extending an existing agent-based framework to include a new and significant behavior, namely parking. In doing so, we have incorporated aspects of the physical infrastructure into the consideration, as well as driver knowledge and behavior. The inclusion of these important aspects of delivery performance allows us to more meaningfully delve into how interventions in parking regulations, driver training, or infrastructure redevelopment might influence the system overall.

Future work might expand upon this by incorporating more complex driver parking behaviors. In particular, we note that the heuristic by which drivers make their deliveries is extremely naive, and may well not track with the actions of the individual drivers. By comparing our generated, synthetic outputs of the driver choice 


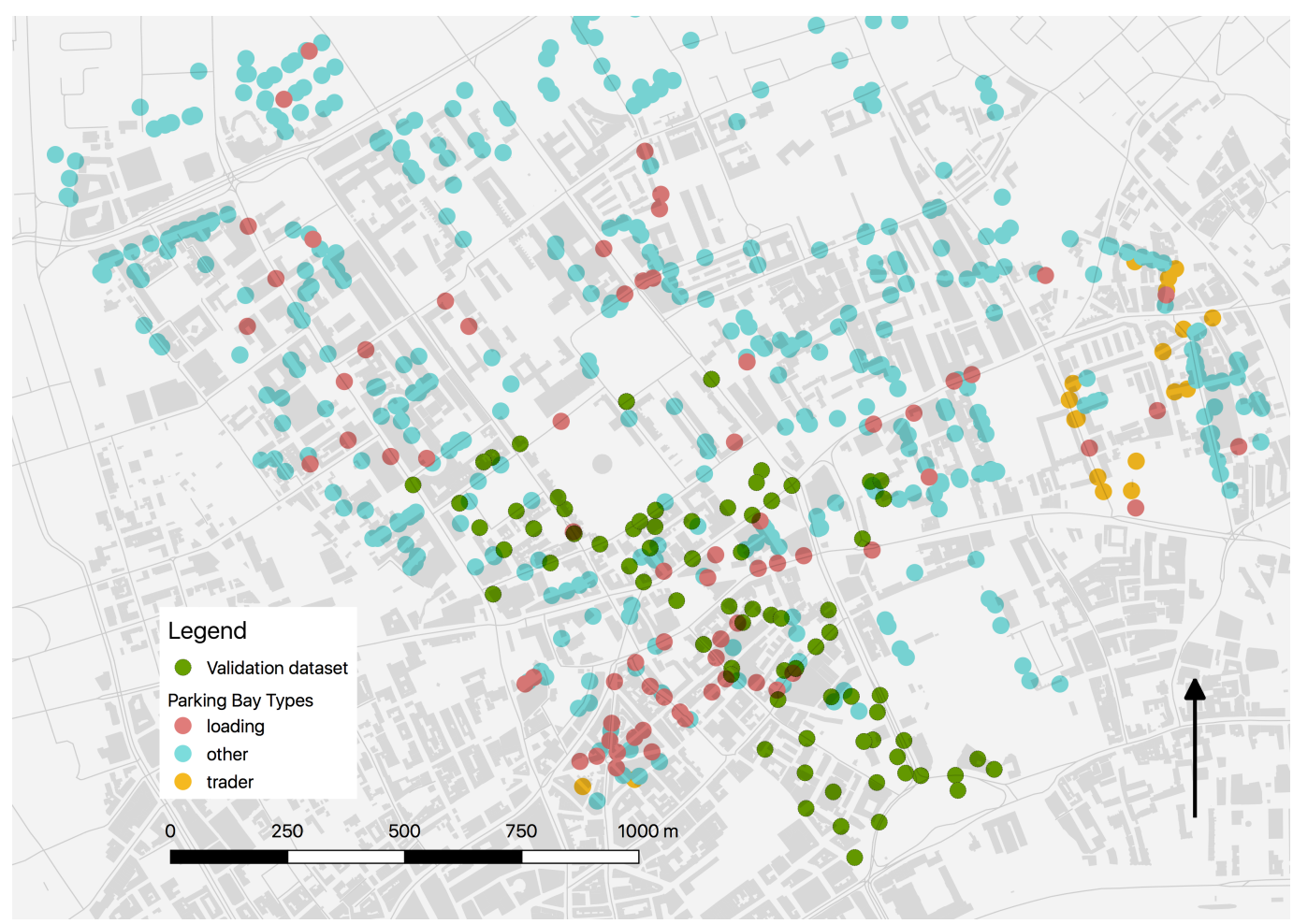

Figure 3: Closeup showing correspondence between parking spots and an example validation dataset.

process with the experiences of real drivers, it may be possible to better frame conversations with subject matter experts and crystallize aspects of driver behavior for further study.

More broadly, the model presented here makes the outcome of different policies and investments a topic which urban planners can more meaningfully compare and discuss. By helping non-specialists explore different trade-offs between proposed interventions, we can help both urban planners and our industry partners understand both how things are now and how they may develop in the future. These changes may have implications on the health of the city, both in terms of the well-being of its citizens and the viability of its economic engine. By investigating this relatively opaque process now, we can build more resilient systems and urban/academic/industrial partnerships to help steward the city's development.

\section{ACKNOWLEDGMENTS}

The authors gratefully acknowledge the EPSRC for funding this work through its financial support of Freight Traffic Control 2050 (www.ftc2050.com), EPSRC Grant Reference: EP/N02222X/1. Responsibility for the contents of the paper rests with the authors.

\section{REFERENCES}

Allen, J., M. Browne, and A. Woodburn. 2014. "London Freight Data Report: 2014 Update”. Technical report, University of Westminster, London.

Allen, J., M. Piecyk, and M. Piotrowska. 2016. "An analysis of road freight in London and Britain: traffic, activity and sustainability". Technical report, University of Westminster, London. 
Allen, J., M. Piecyk, M. Piotrowska, F. McLeod, T. Cherrett, K. Ghali, T. Nguyen, T. Bektas, O. Bates, A. Friday, S. Wise, and M. Austwick. 2018, jun. "Understanding the impact of e-commerce on lastmile light goods vehicle activity in urban areas: The case of London". Transportation Research Part D: Transport and Environment vol. 61, pp. 325-338.

Chen, P., and S. M. Chankov. 2017, Dec. "Crowdsourced delivery for last-mile distribution: An agent-based modelling and simulation approach". In 2017 IEEE International Conference on Industrial Engineering and Engineering Management (IEEM), pp. 1271-1275.

Department for Transport 2016. "Data provided by the Road Freight Statistics Team". Technical report, Department for Transport, London.

Gilbert, N. 2007. "Agent-Based Models".

Heppenstall, A., N. Malleson, and A. Crooks. 2016. ""Space, the Final Frontier": How Good are AgentBased Models at Simulating Individuals and Space in Cities?". Systems vol. 4 (1).

London Borough of Camden 2019. "Parking Bays".

North, M., and C. Macal. 2007. Managing business complexity: Discovering strategic solutions with agentbased modelling and simulation. New York, NY, Oxford University Press.

Roads Task Force 2013. "Technical Note 1: What is the over-arching transport and travel context to which the Roads Task Force needs to have regard?'. Technical report, Transport for London.

Starý, J. 2012. Agent-based Model of Parcel Logistics. Ph. D. thesis.

Wise, S., K. Cheliotis, O. Bates, A. Friday, J. Allen, F. McLeod, and T. Cherrett. 2018. "Using an Agentbased Model to Explore Alternative Modes of Last-Mile Parcel Delivery in Urban Contexts". In Proceedings of the 1st ACM SIGSPATIAL International Workshop on GeoSpatial Simulation - GeoSim 2018, pp. 1-4. New York, New York, USA, ACM Press.

Wise, S., K. Cheliotis, O. Bates, A. Friday, T. J. Cherrett, F. N. McLeod, J. Allen, and M. Piecyk. Under Preparation. "An Agent-based Model of Parcel Delivery".

\section{AUTHOR BIOGRAPHIES}

SARAH WISE is a lecturer for the Centre for Advanced Spatial Analysis of University College London. Her work deals with exploring and forecasting the development of systems involving people, infrastructure, and information, in particular by using agent based modeling. Email: s.wise@ucl.ac.uk

KOSTAS CHELIOTIS is a Research Assistant at the Centre for Advanced Spatial Analysis. His research interests include computational simulations of spatial systems, the intersection of design and human spatial behavior, and interactive visualizations as a tool for efficient communication and dissemination of information. Email: k.cheliotis@ucl.ac.uk

OLIVER BATES is Senior Research Associate at Lancaster University looking at the role of people and digital technology in the demand placed on digital and physical infrastructures. His current work looks to leverage digital technology to redesign for environmental and social justice in homes, on campuses, and of urban freight. Email: o.bates@lancaster.ac.uk

FRASER MCLEOD is a Research Fellow at the University of Southampton with over 30 years' experience on transport-related projects. Recent studies have focused on freight logistics, including servicing of charity donation banks, joint procurement and goods consolidation for large municipal organizations and parcel delivery operations in urban areas. Email: F.N.Mcleod@ soton.ac.uk 
TOM CHERRETT is a Professor of Logistics and Transport Management within the Transportation Research Group at the University of Southampton. He teaches courses in transport planning and Logistics operations management. He researches last-mile logistics and how new technology and operational practice can reduce the negative transport impacts of delivery vehicles. Email: T.J.Cherrett@ soton.ac.uk

JULIAN ALLEN is based at the University of Westminster, where he is involved in research and teaching activities relating to freight transport and logistics. His research interests include freight transport and logistics operations, the role and formulation of freight transport policy, and the history of freight transport. Email: allenj@westminster.ac.uk

MAJA PIECYK is a Reader in Logistics at the University of Westminster. She leads research focusing on the environmental performance and sustainability of freight transport operations. Current projects focus on the optimization of supply chain networks, the efficiency of last-mile urban freight operations, and long-term forecasting of logistics energy demand. Email: M.Piecyk@westminster.ac.uk

TOLGA BEKTAS is Professor of Logistics Management at the University of Liverpool Management School. His research is on mathematical modeling and optimization of problems arising in freight logistics, including network design, vehicle routing and location analysis, with a particular focus on reducing the environmental externalities of road transport. Email: T.Bektas@liverpool.ac.uk 